\title{
Baseline survey results: Integrating adolescent livelihood activities within a reproductive health program for urban slum dwellers in India
}

\author{
Mary Philip Sebastian \\ Population Council \\ Dale Huntington \\ Wesley H. Clark \\ Barbara Mensch \\ Population Council \\ Bela Patel Uttekar
}

Follow this and additional works at: https://knowledgecommons.popcouncil.org/departments_sbsr-rh

Part of the Demography, Population, and Ecology Commons, Health Services Research Commons, International Public Health Commons, and the Vocational Education Commons How does access to this work benefit you? Let us know!

\section{Recommended Citation}

Sebastian, Mary Philip, Dale Huntington, Wesley H. Clark, Barbara Mensch, and Bela Patel Uttekar. 2002. "Baseline survey results: Integrating adolescent livelihood activities within a reproductive health program for urban slum dwellers in India," FRONTIERS Update. New Delhi: Population Council. 

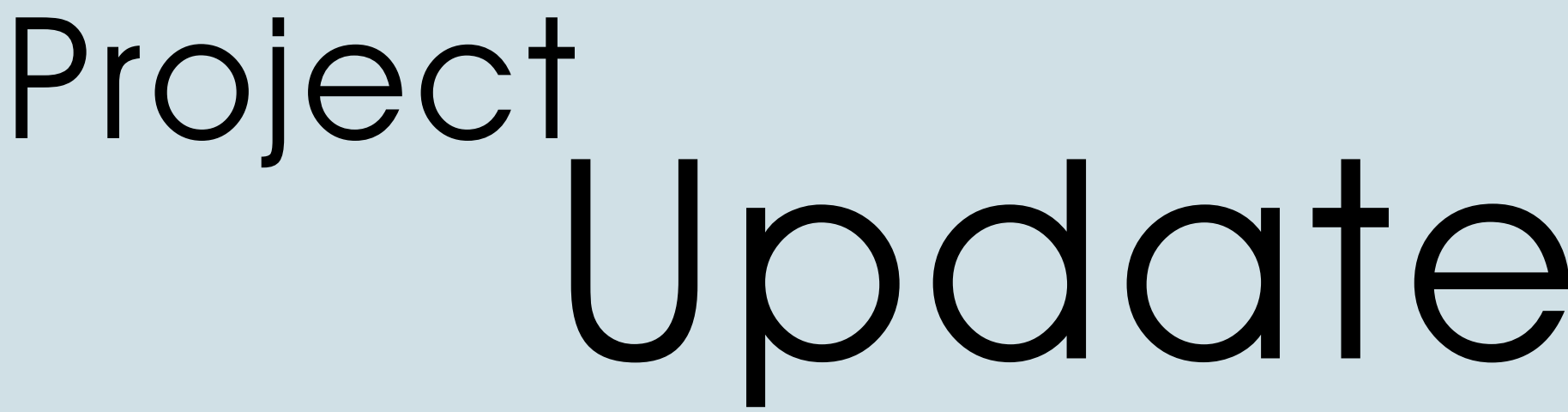

\section{Baseline Survey Results: \\ Integrating Adolescent Livelihood Activities within a Reproductive Health Program for Urban Slum Dwellers in India}

\section{Intrpoducition introduction}

The Population Council's FRONTIERS in Reproductive Health Program and Policy Research Division, in collaboration with CARE India, are conducting an operations research study of an intervention designed to improve the lives and prospects of young women in several urban slum areas of Allahabad, Uttar Pradesh. The project aims to take a preexisting reproductive health program for adolescents and test the feasibility and impact of adding four additional components to it: 1) counseling about savings formation and livelihoods, 2) training in vocational skills, 3) assistance in opening savings accounts and 4) follow-up support. CARE India is managing the larger adolescent reproductive health project, called the Action for Slum Dwellers' Reproductive Health, Allahabad (ASRHA). Previous Project Updates (November 2001) have reported on the design and implementation of the study's intervention and how it is integrated within the CARE



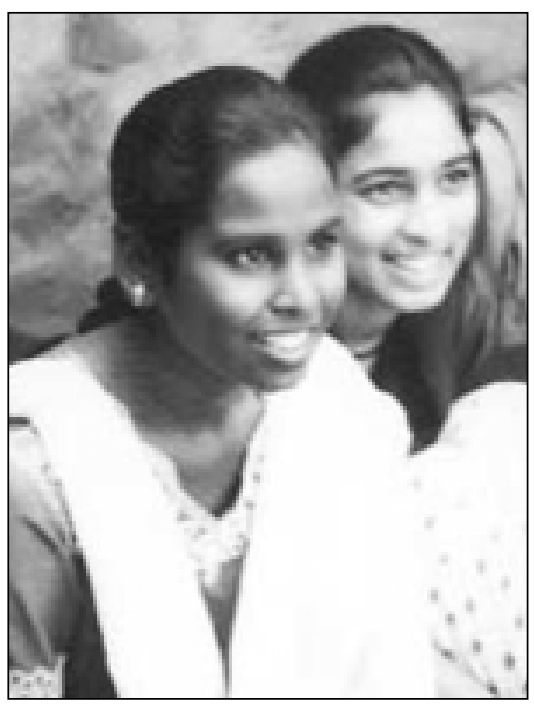

ASRHA Project. This report presents key findings from the study's baseline survey.

\section{Asrha project overview}

Approximately seven years ago CARE India began working in 65 slum areas of Allahabad to provide reproductive health services for approximately 28,000 disadvantaged women through activities that included, among others, the creation of Women's Health Associations. The CARE pilot project was renewed for five years in 1999. 
This new project, Action for Slum Dwellers' Reproductive Health, Allahabad (ASRHA), extends the reach of the original project into 143 slum areas and also includes a new component of providing reproductive health services to 66,000 adolescent boys and girls (aged $10-19$ years). Soon after the beginning of the ASRHA Project, the Population Council and CARE India began discussions on how to examine the additive benefits that might accrue to adolescent girls by providing other types of services to adolescents, such as livelihoods training.

\section{Livelihood activities were} easily integrated since the CARE India strategy takes as its starting point the low priority status of reproductive health concerns among women living in extreme urban poverty in India. The ASRHA Project is designed to demonstrate that multiple benefits are likely to emerge when reproductive health care activities are provided within a context of community participation and development. Adding an additional and related skill to the reproductive health component of the ASRHA Project was consonant with the project's original intent. The experimental intervention was designed to be fully integrated within the ASRHA Project's operations, in order to facilitate its sustained use after the study is completed, and enhance the possibility of replication in other similar project sites that CARE, or other organizations, manage.
Although the ASRHA Project's target population includes boys and girls aged 10-19 years, the additional livelihoods and savings components are designed for girls between the ages of 14 and 19 - otherwise the overlap between the OR intervention and the ASRHA Project is seamless. The ASRHA Project selects peer educators from the slums using a participatory approach that involves community members, and then trains them in reproductive health information, communication skills and group formation techniques. The peer educators also receive training in the content of the IEC materials used by the ASRHA Project (a story book based on a fictional character called "Paro"). After their training is complete, the peer educators work in their slums to form a group of approximately 15-30 adolescent girls. The peer educator presents the information in the Paro storybook and counsels the girls about available reproductive health services and other matters. The peer educators, or assistants (who also receive specialized training by CARE staff, which is shorter and less intense than the training given to the peer educator), identify and provide the same information to other adolescents in the slums who do not come to the group sessions.

\section{Livelihoods and vocational training}

After the peer educators completed the reproductive health education series, they began providing information about livelihoods and savings opportunities as part of the $O R$ project using complementary IEC materials developed for this purpose. OR project staff provided training to the peer educators on the content and requisite information to equip them to conduct group sessions about livelihoods and savings. Population Council and ASRHA Project staff worked together to arrange for the provision of a number of vocational training courses, both in the slums where the girls reside and in the city of Allahabad.

\section{The OR project developed 21} short-term vocational courses each on a different subject that was selected because it responded to the interests of the girls, had good potential for using the skills and reduced gender biases related to what is considered appropriate and inappropriate work for girls. Six to ten courses (each course covers one subject) were offered at a time in a series of batches that began in August 2001 and has continued through May 2002. The selection of courses to be provided in each batch was based on the interest (e.g., enrollment) shown by the girls a minimum of 10 girls was required for a course to be offered. Mehndi (hand or feet painting) was the course almost all the girls were interested in. Other courses arranged by the OR project included tailoring (requiring basic literacy skills that some girls did not possess), creative painting, dhari weaving, mending and embroidery, 


\section{OBJECTIVES}

The operations research study's objective is to foster the development of alternative socialization processes for adolescent girls that enhance the development of positive sexual and reproductive health behaviors.

Immediate objectives:

- The study will integrate vocational counseling, training and follow-up support for married/unmarried adolescent girls coupled with the encouragement of savings formation into CARE's Action for Slum Dwellers' Reproductive Health Project in Allahabad.

- The study will increase participation by married/unmarried adolescent girls in other reproductive health-related activities of the ASRHA Project (e.g., sexual health, hygiene and nutrition).

- The study will foster community acceptance of physical mobility by adolescent girls, strengthen and enlarge positive peer-to-peer support networks, and develop new mentor relationships between younger and older women.

candle making, silver ornament/link making, pot decoration, crochet, jute doll, basic cooking, personal grooming and fabric painting. The operations research project also made arrangements for older girls (18 years and above) to attend government-run courses, such as bee keeping, food preservation, jute craft, macramé, cooking, carpet weaving and block printing. Since many girls wanted to participate in more than one course, the project set a limit for no more than five courses per girl, in order to allow as many newcomers an opportunity as possible. The OR study's intervention phase is currently on-going, and 17 different vocational

subjects have

been taught and

82 classes have

been completed

by 1,200 girls

(many of

whom have

participated,

in multiple

subjects).

Concurrent with

the vocational

skills training,

counseling and

assistance were

provided for

creating savings

accounts at

banks or post

offices. Most

of the new

accounts were

opened at post

offices rather

than banks, since the

procedures were simpler and the amount of money required for the initial deposit was less.

Preliminary tallies indicate that approximately 244 girls have opened savings accounts as a result of the OR project.

During the final phase of the OR study's intervention period, the Population Council is working with the ASRHA Project to provide follow-up support to the "graduates" of the vocational training courses, and to those girls who opened savings accounts, to ensure that they use these new skills. The OR study team held an exhibition in each of the experimental slums in which the girls participated. Girls who have opened savings accounts are being encouraged (and assisted if necessary) in making additional deposits. The ASRHA Project has begun to add the livelihoods element to its activities in other slum areas of Allahabad where the OR study is not being conducted, using the same IEC materials and vocational courses developed by the Population Council study.

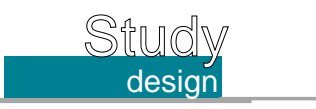

The study uses a quasiexperimental pre- and post-test design that compares the intervention (experimental) group with a comparison (control) group of adolescents. A baseline and end line survey (separated by an intervention period of 12 months) of all adolescents living in the slums, and one of their parents (or guardians), will measure the differential effects of exposure to the various elements of the intervention. A mid-term followup interview conducted with adolescents who participated in one or more of the vocational training sessions and savings formation activities will capture immediate effects of the experimental intervention. The experimental group consisted of five large slums, and the control group consisted of nine smaller slums. A household listing done prior to the study indicated that there are 1,676 households containing approximately 9,900 persons in the control group and 1,716 households containing approximately 10,000 persons in the experimental group. 
Baseline

survey methodology

All of the adolescents between

14-19 years who have been living in the study areas for at least a year and expect to remain for another year were included in the baseline survey at the time of the household listing that identified eligible subjects, prior to administering the informed consent form (both married and unmarried, inschool and out-of-school, boys and girls). In addition one of the parents or a recognized guardian who was older than 25 years within each household was targeted for interviews. The baseline survey was conducted before the ASRHA Project started the group formation activities and before any reproductive health or vocational training activities were conducted in either the control or experimental sites.

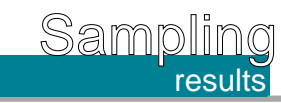

Although earlier listings of the households within each slum area were provided to the research teams, the baseline survey conducted a mapping exercise to determine the exact number of households and eligible adolescents. This preliminary step before conducting the baseline survey revealed many of the difficulties of working in urban slums, including fixing boundaries of the slum versus non-slum areas, and arriving at a functional definition of household. Many structures are temporary shelters for migrant laborers, and others are dwellings that are locked shut and are semi-abandoned. The latter category required the study to go back and validate whether households that had been listed in the sampling frame were abandoned or not eight months after the baseline survey. The results from the locked-house validation study were used to determine a final response rate for the study.

In total the study identified 6,401 households and was able to successfully contact at least one occupant in $95 \%$ of these households $(n=6,086)$.

Approximately $57 \%(n=181)$ of the 315 households that were not contacted did contain residents (according to reports from neighbors) even though no one was evidently living in the house either at the time of the baseline survey or the lockedhouse validation study. About one-quarter (27\%) of the households that were not successfully contacted had evidence of residents who worked odd hours and could not be contacted, either at the time of the baseline (at least three visits were made to each household) or at the time of the locked-house validation study. The remaining $15 \%$ of the missing households were not contacted for other reasons.

The results from the household listing revealed that 2,452 households had 4,284 eligible adolescents of which 3,199 completed interviews for the baseline survey -- a response rate of $75 \%$. The principal reason eligible adolescents were not included in the baseline

\section{THE BASELINE SURVEY measured the following domains using a} standardized questionnaire administered by trained interviewers (of the same sex as the respondents). The Allahabad Livelihoods Study questionnaire used many of the same items as other Population Council studies on adolescence reproductive health so that the results will be comparable across countries. Information on the following domains was collected:

- Demographic information on respondent

- Family background

- Respondent's education and training history

- Livelihood and employment history

- Time use pattern

- Mobility, autonomy, gender role attitudes and behavior

- Knowledge of reproductive health

- Knowledge of contraceptive methods

- Marriage process

- Reproductive history

- Self-efficacy

- Connectedness and friendship

- Alcohol and drug use. 
survey $(93 \%$ of the cases, $n=1,013$ ) was an inability to find the adolescent at home after having made at least three follow-up visits at different times and setting appointments in advance through other family members. The remainder of the adolescents who were not included in the baseline survey either refused to take part in the study $(n=28)$ or did not complete the interview $(n=44)$.

A total of 2,014 parents or guardians completed the baseline parental interview (82\% of the 2,452 households). Among the 438 parents who did not take part in the survey, $54 \%(n=237)$ were unavailable, an additional $29 \%$ failed to complete the interview after beginning $(n=128)$, and
$17 \%(n=73)$ refused to take part in the study.

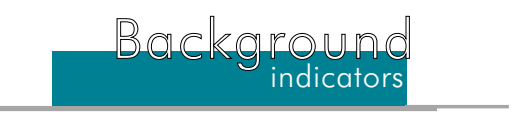

Overall about $53 \%$ of the baseline sample is composed of girls and $47 \%$ of boys, $(n=3,199)$. The number of respondents is larger in the study's experimental group $(n=1,913)$ than in the control group $(n=1,286)$, even though the preliminary mapping exercise and pre-study information suggested that the populations of the slum areas used for each study group were about the same. The baseline survey includes an assessment of several background characteristics, which are summarized in Table 1 (below).
The results presented in Table 1 indicate that the two study groups are quite similar for both the boys and girls, with a few notable exceptions. Slightly more than one-half of the mothers and about one-fifth of the fathers of the adolescents in both study groups are illiterate. There is a small, but statistically significant difference in the proportion of the boys' fathers who are illiterate by study group. A statistically significant yet extremely small difference is observed in the proportion of boys who have ever attended school by study group.

Interestingly, only one parent resides in about one-quarter of the households in both study groups for all adolescents.

The results presented in Table 1

\section{Table 1: Comparison between experimental and control sites, Allahabad}

\begin{tabular}{lcccc} 
& \multicolumn{2}{c}{ Boys } & \multicolumn{2}{c}{ Girls } \\
& $\begin{array}{c}\text { Control } \\
(\mathbf{n}=615)\end{array}$ & $\begin{array}{c}\text { Experimental } \\
(\mathbf{n}=901)\end{array}$ & $\begin{array}{c}\text { Control } \\
(\mathbf{n}=671)\end{array}$ & $\begin{array}{c}\text { Experimental } \\
(\mathbf{n}=1,012)\end{array}$ \\
\hline Mother illiterate \% & 50 & 54 & 56 & 54 \\
\hline Mother - some secondary schooling \% & 19 & 18 & 15 & 14 \\
\hline Father illiterate \% & 18 & $22^{*}$ & 21 & 21 \\
\hline Father - some secondary schooling \% & 41 & 37 & 37 & 35 \\
\hline Both parents live in household \% & 76 & 77 & 76 & 76 \\
\hline Mean age & 16.3 & 16.1 & 15.9 & 16.1 \\
\hline Scheduled caste or tribe \% & 55 & $28^{* * *}$ & 58 & $29^{* * *}$ \\
Backward caste \% & 27 & 38 & 22 & $34^{* * *}$ \\
High caste Hindu \% & 16 & 15 & 18 & 15 \\
Muslim \% & 2 & $18^{* *}$ & 2 & $23^{* * *}$ \\
Unmarried \% & 98 & $99^{*}$ & 96 & 95 \\
\hline Ever attended school \% & 94 & $90^{* *}$ & 86 & 83 \\
Currently attends school (among those & 60 & 58 & 64 & 67 \\
who ever attended) \% & & & &
\end{tabular}

Differences between experimental and control sites significant at: ${ }^{*} p<.05 ;{ }^{* *} p<.01$; $^{* * *} p<.001$

'Note that small differences at the extremes of the range are statistically significant though substantively unimportant. 
reveal differences in the caste and religious composition of the two study groups that will eventually have to be taken into account in the final analysis.

There is a significant difference between the control and experimental sites in the proportion of respondents (both boys and girls) who stated that they belong to a scheduled caste or tribe. The magnitude of this difference between the two study groups' caste composition is lessened if the categories of scheduled and backward castes are combined, but it still remains.

Another difference between the two study groups was evident in their religious composition. .

There is a significantly larger proportion of Muslims living in the experimental slums than in the control slums, for both boys and girls. Anecdotal reports from the field indicate that there are approximately 20 large Muslim families in the experimental sites, but these families account for about onefitth of the boys and almost onequarter of the girls in the study.

The large majority of the adolescents in both study groups reported that they were unmarried, despite the inclusion of married adolescents in the case definition. The small proportion of girls who are married in this study is a function of several factors that are common in many adolescent surveys. Frequently, married girls aged 18 or 19 are not considered adolescents either by themselves or their parents, and hence won't be included in a listing of

"adolescents" living in a household. In the case of India, this problem is compounded by the fact that the Hindi word for adolescent/youth - kishor(i) which was used in the survey, implies that one is unmarried. A contributing factor to the failure to include married adolescents may be the desire to hide an illegal under-age marriage, either from shame or fear of legal repercussions: according to the Child Marriage Restraint Act in 1978, if a child marriage is reported to the appropriate authorities the parents are liable for prosecution.

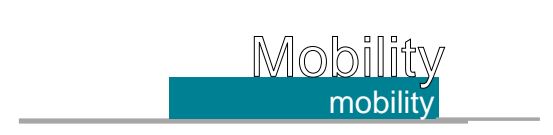

Increasing the community acceptance of adolescent girls' mobility is one of the study's immediate objectives, and the results presented in Table 2 below clearly indicate its appropriateness. Girls reported that they need to seek permission to make visits outside of their homes more frequently than boys, granting them fewer opportunities to interact with their peers or to develop social competencies.

The results presented in Figure 1 (shown in the next page) clearly show that boys are more likely than girls to report multiple places that they have visited in the past six months and that they are more likely to have visited any single area than girls. Multiple responses are possible in this figure, which indicates that not all of the girls in the study reported visiting any place during the past six months: $48 \%$ of girls $(n=812)$ indicated that they have not traveled outside of Allahabad during the past six months as compared to only $24 \%$ of the boys ( $\mathrm{n}=370$ ).

Other results not included in Figure 1 indicate that both boys and girls share an almost equal desire to visit places away from their home: $52 \%$ of the boys and $59 \%$ of the girls in the study said that they would like to go to places outside home more often. However, when asked to name a specific place they would like to visit more often,

\section{Table 2: Percentage of adolescents who need permission}

to visit places outside home

$\begin{array}{lcc}\text { Place } & \begin{array}{c}\text { \% of Girls } \\ (n=1,683)\end{array} & \begin{array}{c}\text { \% of Boys } \\ (n=1,518)\end{array} \\ \text { Neighbor } & 74 & 40 \\ \text { Shop } & 74 & 37 \\ \text { Field } & 49 & 39 \\ \text { Friend } & 85 & 55 \\ \text { Relative } & 95 & 85 \\ \text { Nearby village } & 84 & 75 \\ \text { Nearby health outlet } & 88 & 71 \\ \text { Civil lines- a shopping mall } & 87 & 67\end{array}$


Figure 1 : Places that have been visited within the past six months

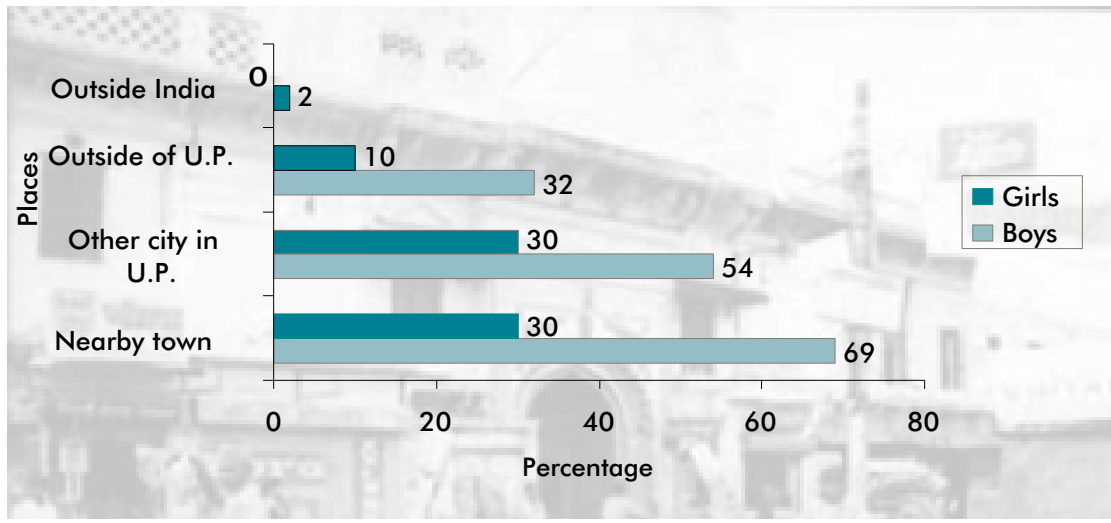

$n=1,683$ (girls), $n=1,518$ (boys); Multiple responses possible.

girls were more likely than boys to give a response: $58 \%$ versus $32 \%$, respectively. A striking difference emerged from the answer to this question about where they would like to visit: $36 \%$ of the girls said they would like to visit their relatives more as compared to only $15 \%$ of the boys. Interestingly, both girls and boys reported an influence of social norms that restricts their mobility, as slightly more than one-half (51\% boys and 58\% girls) acknowledged that venturing outside their homes damaged their own reputations. follow religious customs and visit temples, mosques, churches or other places of worship. However, the findings from the baseline survey shown in Figure 2 indicate that less than one-half of the girls (48\%) in the study reported not having visited a place of worship at least once during the past month. This is compared to the large majority of boys (80\%) who reported that they have visited a place of worship in the past month. The normative restriction on girls' mobility is also shown in Figure 2, which less than one-half of the girls in the baseline survey (44\%) reported that they rarely see their closest friend, compared to only about one-quarter (26\%) of the boys.

Other findings, not shown in Figure 2, indicate that relatively few boys or girls were likely to express feelings of

powerlessness and inefficacy in managing social relations. $17 \%$ of the boys and $26 \%$ of the girls felt strongly that they lacked the ability to convince others or initiate activities in a group, and only $12 \%$ of the boys and $8 \%$ of the girls stated that they were good at solving their daily problems. There do not appear to be large gender-related differences at the study's baseline for this indicator.

\section{allocation and work}

The analysis of how boys and girls use their time is presented by age. It is expected that
The results presented in Figure 2 show that both boys and girls agree that there are no places in the community where unmarried girls can safely congregate for any purpose. This finding reflects local Figure 2 : Perceptions about mobility and ability to move within the neighborhood

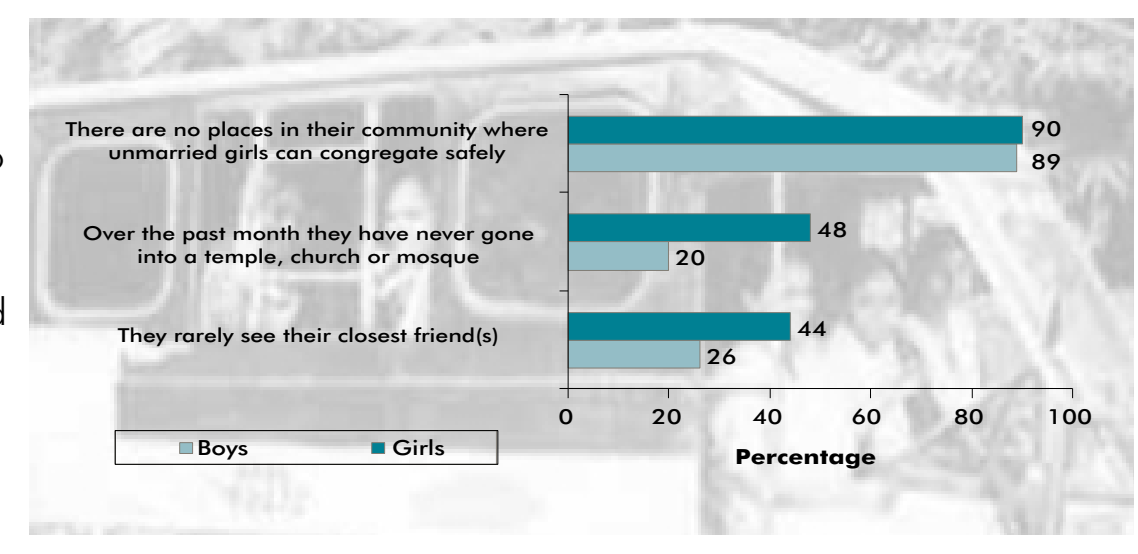
$n=1,683$ (girls), $n=1,518$ (boys) norms governing the limited use of public space by unmarried girls in general. Traditionally both married and unmarried women in India indicates that girls were more likely to report rarely having seen their closest friend in the past month than boys: slightly younger adolescents will spend their time differently than older adolescents, which is shown in Table 3. In general, boys reported spending more time in paid work than girls, and older adolescents spent more time than younger in paid work activities. The average number of hours spent in paid work is almost double 
Table 3: Reported activities during the day before the interview

\begin{tabular}{lcccc}
$\begin{array}{l}\text { Average hours in previous day } \\
\text { spent on:* }\end{array}$ & \multicolumn{2}{c}{$\begin{array}{c}\text { Average hours - } \\
\text { Age of Girls }(n=1,683)\end{array}$} & \multicolumn{2}{c}{$\begin{array}{c}\text { Average hours - } \\
\text { Age of Boys }(n=1,518)\end{array}$} \\
Chores & $14-16$ & $17-19$ & $14-16$ & $17-19$ \\
Education & 4.0 & 4.8 & 0.90 & 1.1 \\
Personal Care (including napping) & 3.9 & 2.8 & 4.7 & 3.2 \\
Recreation & 3.3 & 3.5 & 3.1 & 3.3 \\
Unpaid Work & 2.6 & 2.6 & 3.3 & 3.3 \\
Paid Work & 0.15 & 0.20 & 0.34 & 0.42 \\
Other & 0.10 & 0.17 & 1.5 & 2.6
\end{tabular}

*Does not include time spent sleeping during the night

for older boys (2.6 hours) compared to younger boys ( 1.5 hours). The opposite effect is seen with time spent on education. In general, younger adolescents reported spending more time on their education than older adolescents, and boys reported more time than girls did on educational pursuits. Dramatic differences between boys and girls are seen in the amount of time spent on chores: girls reported spending almost four times as many hours as boys on chores, with both older girls and boys spending more time than the younger adolescents on chores.

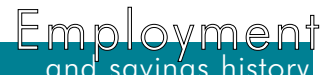

The results presented in Figure 3 are congruent with the time use findings. The proportion of boys who report that they have ever worked for pay is five times greater than the proportion of girls. The magnitude of the gender difference in the proportion who state they are currently

Figure 3 : Employment among girls and boys

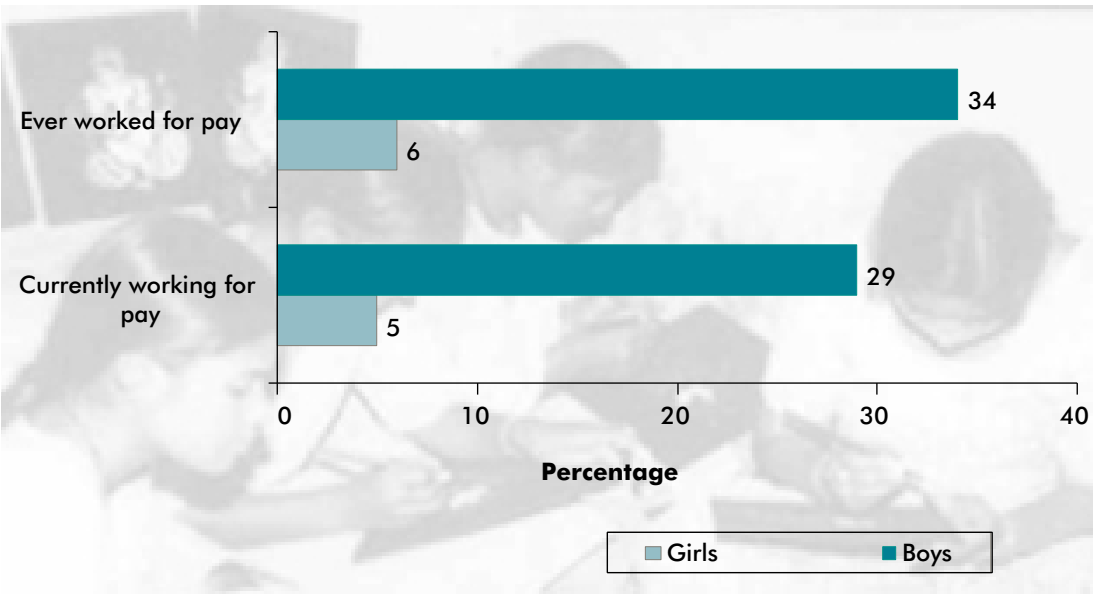

$n=1,683$ (girls), $n=1,518$ (boys)

working for pay is equally great: $29 \%$ of the boys reported they are currently working for pay compared to only $5 \%$ of the adolescent girls.

There are substantial differences in the place of work among those adolescents who reported they are currently working for pay (5\% of the girls and $29 \%$ of the boys), as Figure 4 shows (in the next page). One-half of the adolescent girls who are working for pay reported the location of the work as being their family's home, as compared to only $13 \%$ of the boys. In fact, the second most frequent location of paid work for girls was another family's house (31\%), a location reported by only $9 \%$ of the boys. Work for pay that is done by girls at home most commonly involves the production of light bulb filaments, silver links for simple jewelry and packing materials for storage, in addition to working as domestic help for pay. Adolescent boys who work for pay most commonly said they work in other locations as occasional labor or diverse 
Figure 4 : "Where are you currently working?"

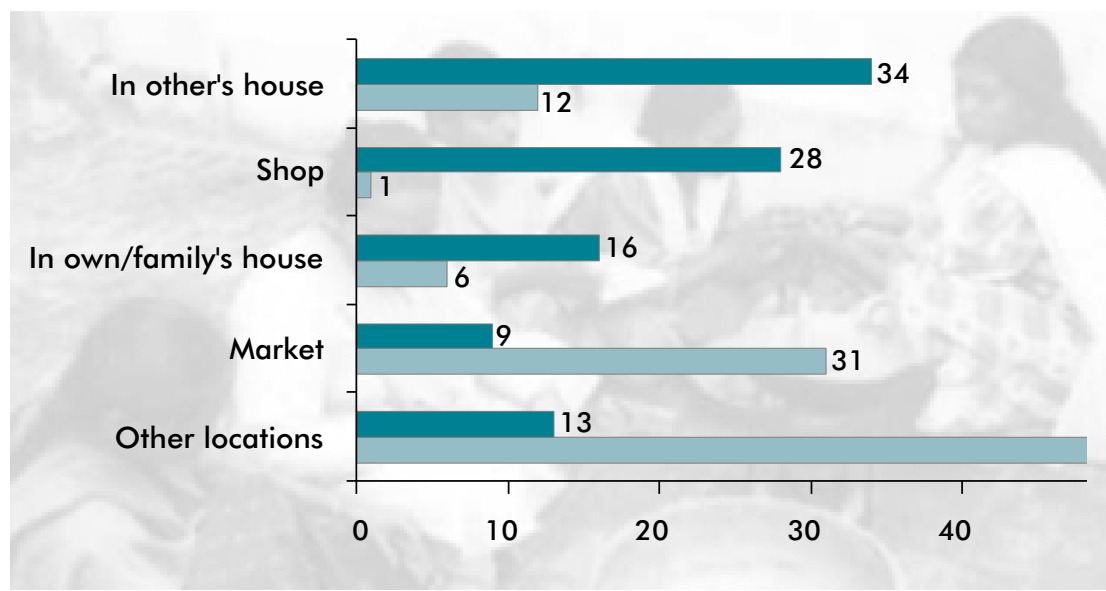

$n=83$ (girls), $n=437$ (boys)

occupations (33\%), the market $(28 \%)$ or a shop (16\%).

\section{Salving
savings}

Overall, slightly more than one-half (54\%) of the adolescent girls in the study reported currently having some rupees saved, as compared to about one-quarter (26\%) of the adolescent boys. The results presented in Figure 5 are for girls only, and show that among those girls who do have some rupees saved, the most common location for the savings is at home. Anecdotal reports suggest that commonly girls are hesitant to open a savings account because of the (mistaken) belief that regulations require joint ownership of the account with one of their parents. Other findings from the baseline survey (not shown in Figure 5) reveal a strikingly different distribution of places where boys keep their savings. Among those boys in the project sites who do have rupees saved, 57\% keep their savings at home, $28 \%$ use a

bank and $16 \%$ keep the savings with a family member or a friend. The greater reliance on banks or other formal savings institutions among boys is, in part, a result of their greater mobility and autonomy (indicated earlier in Table 2).

\section{Knowled}

about vocational training

Prior to the introduction of vocational counseling and training courses by the operations research study, very few adolescent boys or girls had ever received any type of

Figure 5 : Savings practices among adolescent girls

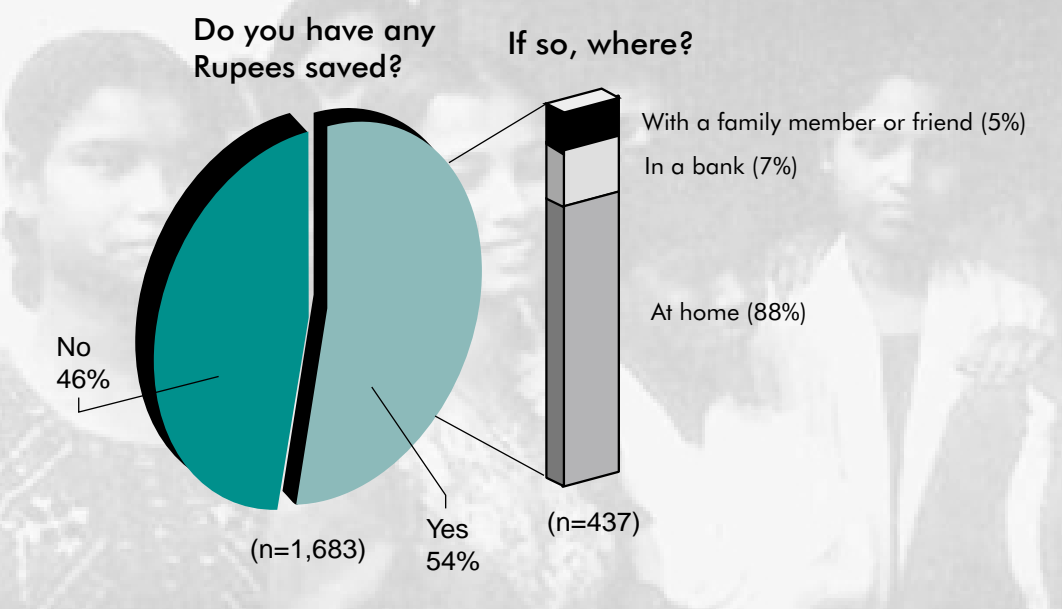

training. Remarkably, an almost equal proportion of boys and girls reported a prior experience with vocational training: $12 \%$ and $13 \%$, respectively as shown in Figure 6 (in the next page). A large majority of the adolescents in the study sites indicated a desire for training. Other findings (not shown in Figure 6) reveal that boys desire different types of courses than girls. The majority of responses to a question about desired types of vocational courses fall into two categories, for boys: computer training $(41 \%)$ or other technical and manual skills 
study's intervention, as there is a high degree of correspondence between the

knowledge. For example, 97\% of the girls reported knowledge about menstruation

Figure 6 : Past vocational training and course preference by sex

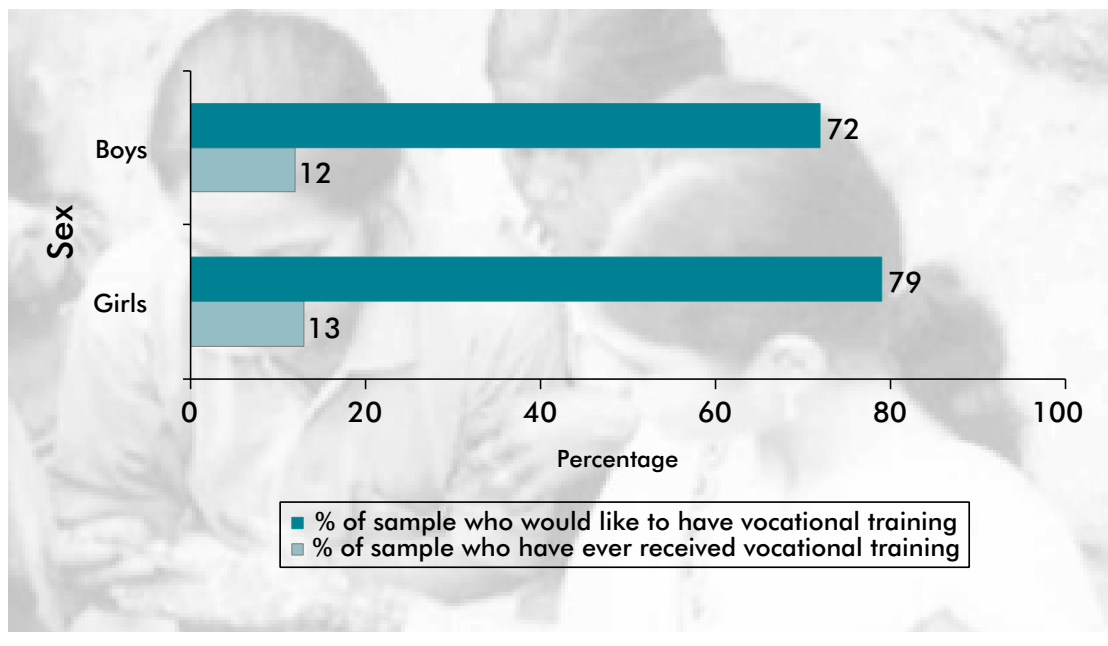

$n=1,683$ (girls), $n=1,518$ (boys)

courses that are offered by the project and the type of courses that are preferred by the adolescents living in the study sites.

\section{Reprodnctive} health knowledge compared to $39 \%$ of the boys. Whereas $88 \%$ of the boys in the study reported knowing about sexual intercourse and the process of conception compared to only $42 \%$ of the girls.

the boys and $2 \%$ of the girls). Although the majority of the respondents reported knowing at least one contraceptive method $(94 \%$ boys and $91 \%$ girls), only about one-third (32\%) of the girls reported knowing about condoms spontaneously as compared to $82 \%$ of the boys (not shown in Figure 7). Other findings also show that girls' knowledge about condoms was weak: only $37 \%$ of the girls knew that condoms can protect against becoming infected with HIV/AIDS, as compared to $84 \%$ of the boys.

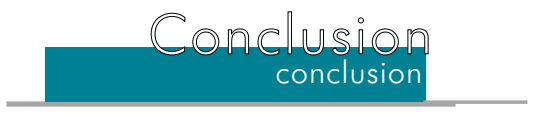

The results from the operations research study's baseline survey indicate that while there are some important differences between the study's experimental and control The baseline Figure $7:$ Knowledge of reproductive health issues survey results indicate that there are several areas of insufficient knowledge and awareness about reproductive health matters among both adolescent boys and girls in the study sites.

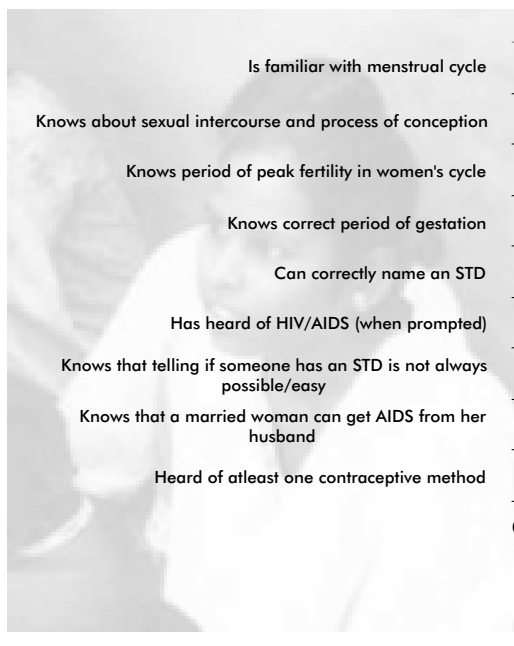

$n=1683$ (girls), $n=1518$ (boys)

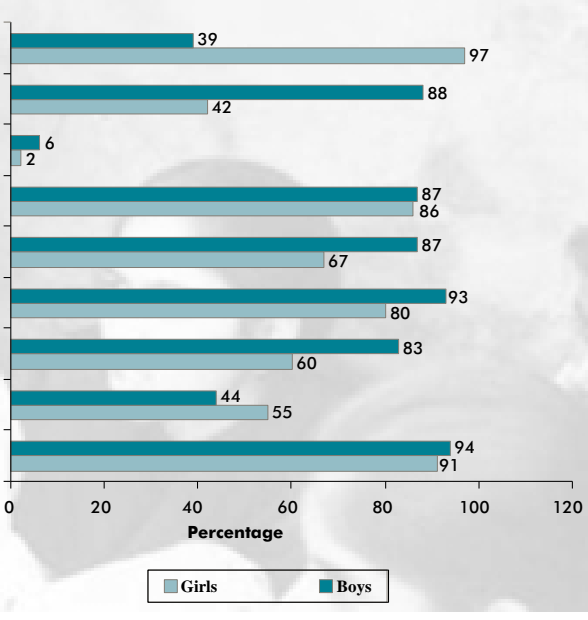

groups (primarily with the religious and caste characteristics), overall the two groups are similar in their general characteristics. Subsequent reports from the post-test survey will explore and report on the
Overall the girls were less likely than boys to report knowledge about most of the indicators listed in Figure 7, although on some subjects (e.g., menstruation) girls were more likely than boys to report
However, for certain indicators, knowledge among both boys and girls were remarkably low. For example, very few adolescents in the survey knew about the fertile period of a woman's menstrual cycle $(6 \%$ of effects of the intervention as demonstrated by the comparison of the experimental and control group results. This report clearly indicates the appropriateness of the intervention, particularly in the differences between boys 
and girls with respect to mobility, time use patterns and savings and work experience. The types of courses that the operations research study provides for the participating girls were shown to be a good match given the current interests of the girls and the strategy of integrating the vocational training and savings formation activities within the on-going reproductive health outreach work of CARE's ASRHA Project. The reproductive health knowledge of girls who live in the study sites is generally weak. The combined effect of the ASRHA Project and the livelihoods activities of this operations research study should make a positive impact on the lives of the young women in Allahabad.

\section{Refrerence \\ reference}

Project Update, November 2001. "Integrating Adolescent Livelihood Activities within a Reproductive Health Program for Urban Slum Dwellers in India." Frontiers in Reproductive Health, Population Council:

New Delhi.

\section{(P) Population Council}

The Population Council is an international nonprofit, nongovernmental institution that seeks to improve the wellbeing and reproductive health of current and future generations around the world and to help achieve a humane, equitable, and sustainable balance between people and resources. The Council conducts biomedical, social science, and public health research and helps build research capacities in developing countries. Established in 1952, the Council is governed by an international board of trustees.

Copyright (C) 2002 The Population Council Inc.

This publication was made possible through support provided by the Office of Population, Health and Nutrition of the UNITED STATES AGENCY FOR INTERNATIONAL DEVELOPMENT (USAID), under the terms of Cooperative Agreement Number HRN-A-00-98-00012-00. The opinions expressed herein are those of the author and do not necessarily reflect the views of USAID.

\section{Frontiers in Reproductive Health Project} UPDATE, JUNE 2002

- Contributors:

Mary Philip Sebastian, Ph.D.

Dale Huntington, Sc.D.

Wesley Clark MPH.

Barbara Mensch, Ph.D.

Bella Patel Ph.D.

- Visualisation and Design:

Sohini Roychowdhury, PGDPR

- Acknowledgement:

Chris Parker, M.A.*

*(Not Population Council staff)

- Produced and Printed by:

macro graphics.comm pvt. Itd., New Delhi

For more information on the Frontiers Project, OR TO BE INCLUDED ON OUR MAILING LIST, PLEASE

CONTACT US AT:

53 Lodi Estate, 3rd Floor

New Delhi 110003

India

Tel: 91-11-461-0913/4

frontiers@pcindia.org 


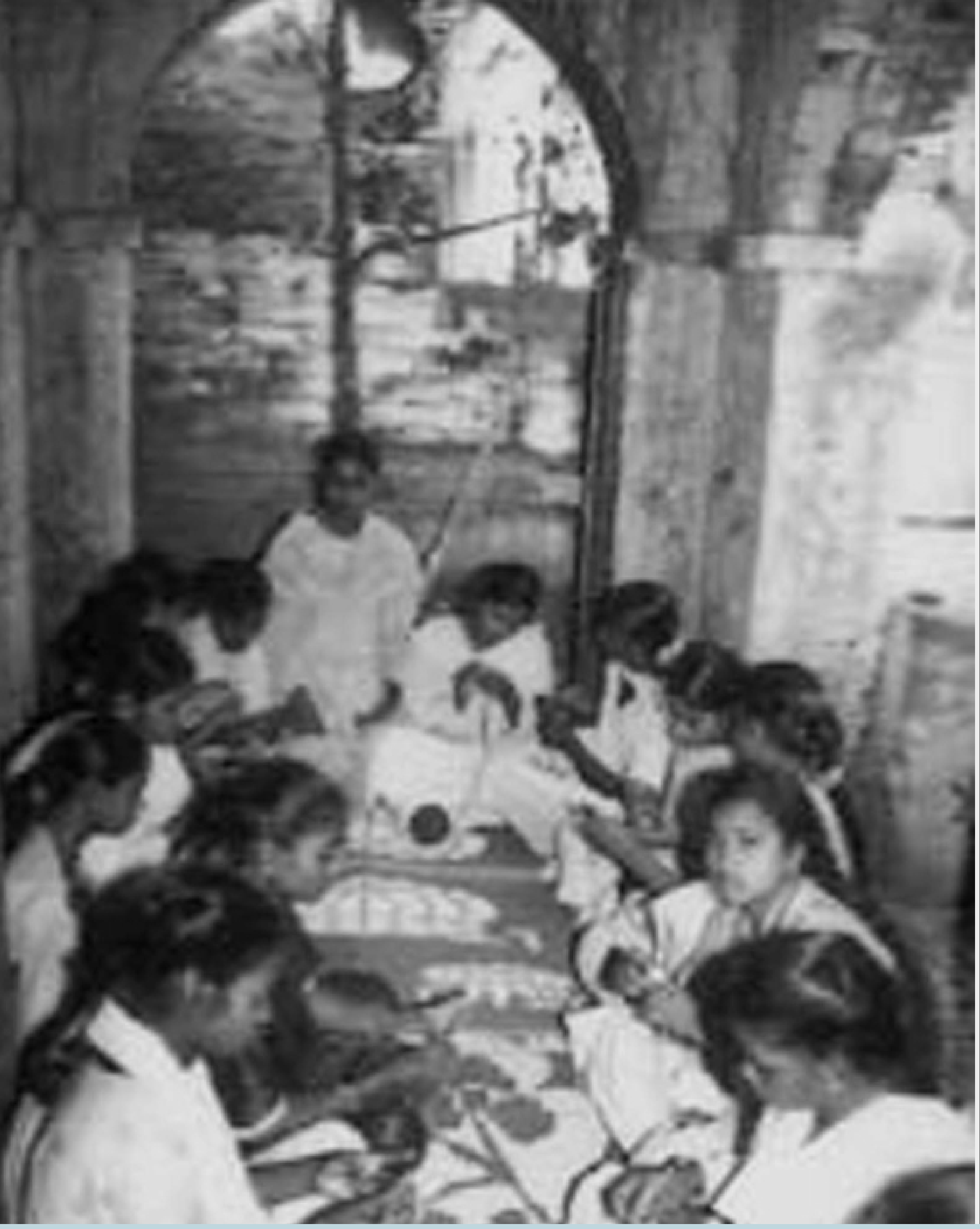

Frontiers IN Reproductive HeALTH

- INDIA

53 Lodi Estate

3rd Floor

New Delhi 110003

Tel: 91-11-461-0913/4

E-mail: frontiers@pcindia.org
- WASHINGTON

4301 Connecticut., N.W.

Suite\#280

Washington, D.C. 20008

Tel: 1-202-2379400

E-mail: frontiers@pcdc.org 